\title{
Effects of Pimobendan on Adverse Cardiac Events and Physical Activities in Patients With Mild to Moderate Chronic Heart Failure
} The Effects of Pimobendan on Chronic Heart Failure Study (EPOCH Study)

\author{
The EPOCH Study Group*
}

\begin{abstract}
The long-term beneficial effects of pimobendan in the treatment of chronic heart failure (CHF) have not been established, so the present trial compared pimobendan ( 1.25 or $2.5 \mathrm{mg}$ twice daily) vs placebo in 306 patients with stable New York Heart Association class IIm or III CHF, and a radionuclide or echocardiographic left ventricular ejection fraction (LVEF) $\leq 45 \%$ despite optimal treatment with conventional therapy, for up to 52 weeks in a double-blind protocol. At the end of the 52 weeks of treatment, combined adverse cardiac events had occurred in 19 patients in the pimobendan group (15.9\%) vs 33 patients in the placebo group $(26.3 \%)$. The cumulative incidence of combined adverse cardiac events was $45 \%$ lower $(95 \%$ confidence interval of hazard ratio: $0.31-0.97, \log$-rank test: $\mathrm{p}=0.035$ ) in the pimobendan group than in the placebo group. Death and hospitalization for cardiac causes occurred in 12 patients in the pimobendan group (10.1\%), vs 19 patients in the placebo group (15.3\%), but without significant difference. Treatment with pimobendan also increased the mean Specific Activity Scale score from $4.39 \pm 0.12$ at baseline to $4.68 \pm 0.15$ at 52 weeks $(\mathrm{p}<0.05)$. In conclusion, long-term treatment with pimobendan significantly lowered morbidity and improved the physical activity of patients with mild to moderate CHF. (Circ J 2002; 66: 149-157)
\end{abstract}

Key Words: Chronic heart failure; Inotropic drugs; Morbidity; Physical activity; Pimobendan

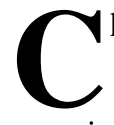
hronic heart failure (CHF) is a complex clinical syndrome linked to abnormal cardiac function. Because it is characterized by depressed cardiac pumping, interventions that increase myocardial contractility would be expected to slow the progression of the disease and improve survival! The production of cyclic adenosine monophosphate (AMP) is impaired in patients with heart failure ${ }^{2}$ and although pharmacologic agents that increase the concentration of intracellular cyclic AMP cause marked short-term hemodynamic improvement, several clinical trials have shown that chronic administration increased the mortality of patients with $\mathrm{CHF}^{1,3}$ The mechanism of such accelerated mortality remains incompletely understood.

Pimobendan, a benzimidazole pyridazinone derivative, is positively inotropic through its combination of a calciumsensitizing effect and a cyclic AMP-dependent mode of action.-6 In healthy young volunteers, pimobendan has a bioavailability of $70 \%$ and undergoes hepatic metabolism to an active metabolite, UDCG 212, which is more potent than the parent compound as a phosphodiestrase III inhibitor and an inotrope in vitro. This metabolite has also been

(Received July 27, 2001; revised manuscript received November 2, 2001; accepted November 7, 2001)

*The investigators and institutions participating in the EPOCH study are listed in Appendix.

Mailing address: Shigetake Sasayama, MD, Director of the Hamamatsu Rosai Hospital, E. Professor of Graduate School of Medicine, Kyoto University, 25 Shogen-cho, Hamamatsu, Shizuoka 430-8525,

Japan. E-mail: sasayama@wonder.ocn.ne.jp reported to have more effect on the calcium sensitivity of human ventricular myofilaments? Early clinical studies of the acute hemodynamic effects of a single oral dose of pimobendan administered to patients with severe CHF have demonstrated a significant improvement in left and right ventricular function, peaking $3-5 \mathrm{~h}$ after drug intake?-10 Randomized, placebo-controlled trials in patients with CHF have also shown that pimobendan was therapeutically effective when added to conventional drug regimens, with or without digitalis!1-16 However, all these data are derived from relatively small samplings and the follow-up periods have not been sufficiently long, except for the PICO trial! ${ }^{15}$

In view of these findings, the present study was designed to examine the long-term effects of pimobendan with flexible doses within the approved daily dose range on adverse cardiac events and physical activity in Japanese patients with CHF.

\section{Methods}

\section{Patient Population}

Patients between the ages of 20 and 85 years were eligible for enrollment into the study if they (1) had clinically stable, New York Heart Association (NYHA) functional class IIm in the subcategory of NYHA II, which means moderate limitation of physical activity, or NYHA functional class III chronic heart failure, (2) had remained symptomatic despite conventional therapy with digitalis, diuretics, angiotensin-converting enzyme (ACE) inhibitors, nitrates, Ca-blockers, $\beta$-blockers or antiarrhythmic etc for 


\begin{tabular}{|c|c|c|}
\hline & Pimobendan & Placebo \\
\hline No. patients considered for enrollment & \multicolumn{2}{|c|}{306} \\
\hline Not eligible & & \\
\hline Randomized (n) & 147 & 151 \\
\hline \multicolumn{3}{|l|}{ Withdrawn before treatment initiation ( $n$ ) } \\
\hline Change in clinical status & 5 & 5 \\
\hline Consent withdrawn & 1 & 2 \\
\hline Protocol violation (loss of follow up) & 2 & 1 \\
\hline Sudden death & 0 & 1 \\
\hline Change in background treatment & 0 & 1 \\
\hline Unexpected hospitalization & 0 & 1 \\
\hline Total & 8 & 11 \\
\hline Treatment initiated ( $n$ ) & 139 & 140 \\
\hline Withdrawn from analysis ( $n$ ) & 1 & 2 \\
\hline Full analysis data set & 138 & 138 \\
\hline Treatment completed & 111 & 113 \\
\hline \multicolumn{3}{|l|}{ Treatment discontinued } \\
\hline Study exits & 9 & 7 \\
\hline Drug-related adverse events & 14 & 9 \\
\hline Non drug-related adverse events & 4 & 9 \\
\hline
\end{tabular}

at least 4 weeks without any changes in the drug regimen, and (3) had a radionuclide or echocardiographic left ventricular ejection fraction (LVEF) $\leq 45 \%$ measured within 2 months of enrollment. Continuation of treatment with digitalis, diuretics, ACE inhibitors, nitrates, Ca-blockers and $\beta$-blockers was permitted, but other cardiotonic agents, including vesnarinone, denopamine, and docalpamine were prohibited.

Exclusion criteria from enrollment included severe ventricular and atrial arrhythmias, advanced atrioventricular block, stenotic, obstructive or infectious heart disease, acute myocardial infarction within the previous 3 months, cardiac surgery within the previous 3 months, severe cerebrovascular, respiratory, hepatic, renal or hematological disease, or the presence of another life-limiting condition. Pregnant and nursing women were also excluded, as well as nonpregnant women of childbearing age unless they had been sterilized.

All patients gave written informed consent to participate in the study and the study protocol was approved by the Institutional Ethical Review Board of each participating institution.

\section{Study Design}

A preliminary patient evaluation was performed 2-4 weeks before the anticipated time of randomization into the study. Background medications remained unchanged, and patients were ultimately entered into the study if they had remained clinically stable during the pre-treatment period while baseline clinical tests were performed, including chest roentgenogram, 12-lead ECG, echocardiogram, measurement of serum atrionatriuretic peptide (ANP) level, routine blood chemistry and urinalysis. ANP was determined with the immunoradiometric assay method (IRMA) 17 Echocardiographic and radionuclide methods ${ }^{18-20}$ were used to determine the LVEF in 93 and 9 patients, respectively, of the pimobendan group, and 96 and 14 patients, respectively, of the placebo group. Physical activity was determined from the Specific Activity Scale (SAS) questionnaire, which has been validated in patients with $\mathrm{CHF}^{21}$

After gathering all baseline observations, the patients were randomly assigned to double-blind treatment for 52 weeks with pimobendan, $1.25 \mathrm{mg}$ twice daily, vs matching placebo. The dose could be increased to $2.5 \mathrm{mg}$ twice daily if the patient had no improvement in the signs or symptoms of heart failure. Outpatient visits were scheduled every 4 weeks during which a physical examination was performed, the SAS questionnaire resubmitted, and adverse events were recorded. At weeks 4, 24 and 52 the evaluation also included an ECG, echocardiogram, chest roentgenogram, measurements of serum ANP levels, routine blood chemistry and urinalysis. The patients were treated with the study medication for up to 52 weeks, or until the primary endpoints (described later) occurred. At the end of 52 weeks, if the treatment was judged to have been clinically effective, its prescription could be continued with the written consent of the patient.

\section{Randomization Procedure}

The randomization code was prepared in sets of 6 patients according to a block design. Treatment was assigned by a registration office according to a code using a dynamic balancing method allowing adjustments for 4 variables, including LVEF (>30\% vs $\leq 30 \%$ ); underlying heart disease (dilated cardiomyopathy vs ischemic heart disease vs valvular insufficiency), NYHA functional class (IIm vs III) and enrolling institution.

\section{Study Endpoints}

The primary endpoints were adverse cardiac events, including death from heart failure, sudden/arrhythmic cardiac death, and hospitalization for worsening heart failure. The secondary endpoints were a decrease by $\geq 1$ Mets in the SAS questionnaire score for at least 3 months as compared with the baseline, a need for modification of the background treatments with a new addition or an increase of the concomitant drugs for at least 4 weeks and/or with intravenous administration of a cardiotonic agent for at least $4 \mathrm{~h}$ because of worsening heart failure, and death from noncardiac and other cardiac causes. All adverse cardiac events were regularly reviewed by an independent Study Event Committee.

\section{Statistical Analysis}

All statistical analyses were performed with the statistical package SAS(r), version 8.0. The calculated sample 
Table 2 Baseline Clinical Characteristics of Each Treatment Group

\begin{tabular}{|c|c|c|}
\hline & Pimobendan $(n=138)$ & Placebo $(n=138)$ \\
\hline Age (years) [range] & $62.0 \pm 10.9[24-84]$ & $65.8 \pm 9.4[32-84]$ \\
\hline$M / F(\%)$ & $104 / 34(75.4 / 24.6)$ & $99 / 39(71.7 / 28.3)$ \\
\hline \multicolumn{3}{|l|}{ Underlying heart disease, $n(\%)$} \\
\hline Dilated cardiomyopathy & $86(62.3)$ & $85(61.6)$ \\
\hline Ischemic heart disease & $46(33.3)$ & $47(34.1)$ \\
\hline Others & $6(4.3)$ & $6(4.3)$ \\
\hline \multicolumn{3}{|l|}{ NYHA class, $n(\%)$} \\
\hline IIm & $93(67.4)$ & $89(64.5)$ \\
\hline III & $44(31.9)$ & $49(35.5)$ \\
\hline $\operatorname{LVEF}(\%)$ [range] & $33.1 \pm 8.6[13-45]$ & $32.6 \pm 8.6[7-45]$ \\
\hline SAS (Mets) & $4.4 \pm 1.4$ & $4.3 \pm 1.4$ \\
\hline$A N P(p g / m l)$ & $52.4 \pm 2.7$ & $54.8 \pm 2.5$ \\
\hline $\operatorname{CTR}(\%)$ & $54.5 \pm 6.3$ & $55.2 \pm 6.2$ \\
\hline Duration of CHF (months) & $44.9 \pm 47.4$ & $41.6 \pm 47.7$ \\
\hline \multicolumn{3}{|l|}{ Blood pressure $(\mathrm{mmHg})$} \\
\hline Systolic & $120.9 \pm 17.4$ & $122.9 \pm 17.2$ \\
\hline Diastolic & $73.2 \pm 10.3$ & $71.4 \pm 9.8$ \\
\hline Heart rate (beats/min) & $74.6 \pm 13.8$ & $74.2 \pm 12.5$ \\
\hline \multicolumn{3}{|l|}{ Concomitant medication } \\
\hline Digitalis & 81 & 82 \\
\hline Diuretics & 116 & 109 \\
\hline ACE inhibitors & 93 & 95 \\
\hline Nitrates & 59 & 62 \\
\hline Ca-blockers & 21 & 24 \\
\hline$\beta$-blockers & 35 & 27 \\
\hline Antiarrhythmic & 46 & 40 \\
\hline \multicolumn{3}{|l|}{ Daily dose of study medication prescribed, $n(\%)$} \\
\hline Low dose (1.25 mg bid only for pimobendan group) & $107(77.5)$ & $111(80.4)$ \\
\hline High dose (1.25 $\mathrm{mg}$ and $2.5 \mathrm{mg}$ bid for pimobendan group) & $31(22.5)$ & $27(19.6)$ \\
\hline
\end{tabular}

NYHA, New York Heart Association; LVEF, left ventricular ejection fraction; SAS, specific activity scale; ANP, serum atrionatriuretic peptide; CTR, cardiothoracic ratio; $C H F$, congestive heart failure; $A C E$, angiotensin-converting enzyme. Values are mean $\pm S D$.

size was based on assumptions of 1-year cumulative incidence rates of $27-29 \%$ in the placebo group and hazard ratio of $0.4-0.5^{14,22}$ for combined primary and secondary endpoints. The target number of patients was calculated to be 130 per treatment group, based on a 5\% type I error, a 2sided test, and an $80 \%$ power, using Freedman's formula? 3

The primary analysis was based on intention-to-treat, and included all primary and secondary adverse cardiac events which occurred in each patient during the 52-week treatment period. In this analysis, the cumulative incidence rates were calculated with respect to the time to the first combined primary and secondary endpoints by the KaplanMeier method in each treatment group and compared by log-rank test. The hazard ratio was estimated by Cox's regression.

Secondary efficacy analyses consisted of comparisons of treatment-associated changes in SAS, LVEF, ANP levels, cardiothoracic ratio (CTR) and NYHA functional class between the 2 groups of patients. An analysis of covariance using a baseline value as a covariate was used to examine the differences in response between the 2 treatment groups. The response at 52 weeks was used as the response variable and missing values were imputed using the Last-Observation-Carried-Forward approach.

Changes in NYHA functional class were summed in each group and the difference in response was tested by Wilcoxon's test. Unless specified otherwise, values are presented as mean $\pm \mathrm{SD}$. $\mathrm{P}$ values $<0.05$ were considered statistically significant.

\section{SAS Scores Analysis}

Time trends for the SAS scores were analyzed by fitting a general linear model for repeated measures. The least square means (LSMeans) were calculated for 14 time points, including baseline values, and a model with interaction terms between time points and groups, using a compound symmetry structure, was used for a working covariance matrix, and an empirical robust variance for the calculation of standard error. The overall type III effect of groups and time points, as well as interaction terms, was tested using a model with the baseline value as a covariate. Lower SAS scores corresponded to the worst physical condition.

Missing values were (1) death: a value of 0 was assigned after death; (2) hospitalization: the value at the hospitalization was imputed after the patient was admitted to the hospital. If the value was not available, the mean value for the hospitalization was calculated from all the available hospitalized cases; and (3) dropout or treatment discontinuation: a mean value was calculated from all data available for each patient before dropout or discontinuation.

\section{NYHA Functional Class Analysis}

Changes in NYHA functional class were categorized as improved, unchanged, or aggravated. Patients in NYHA class III heart failure at baseline were considered to have functionally improved if they were in NYHA class I, IIs or IIm at the end of the study, and to have worsened if they were in NYHA class IV or had experienced a primary adverse cardiac event by the end of the study. Likewise, patients in NYHA class IIm heart failure at baseline were considered to have improved if they were in NYHA class I or IIs at the end of the observation period, and to have worsened if they were in NYHA class III or IV, or had 
Table 3 Cardiac Events Included in the Primary Analysis in Each Treatment Group

\begin{tabular}{lccc}
\hline \hline & \multicolumn{3}{c}{ No. of patients with events } \\
\cline { 2 - 4 } & Pimobendan & Placebo & Total \\
\hline Primary endpoints & $12(1)$ & $19(4)$ & $31(5)$ \\
$\quad$ Total & 1 & 1 & 2 \\
$\quad$ Sudden cardiac death & $11(1)$ & $18(4)$ & $29(5)$ \\
$\quad$ Hospitalization because of progressive CHF & 0 & 0 & 0 \\
Death from progressive CHF & 8 & 18 & 26 \\
Secondary endpoints & 6 & 14 & 20 \\
$\quad$ Total & 2 & 4 & 0 \\
Decrease in SAS $(\geq 1$ Mets) & 0 & 0 & 52 \\
Addition or increase in doses of background medications & & & 5 \\
Non-cardiac and other cardiac deaths & 19 & 33 & 5 \\
Combined number of primary and secondary endpoints & & & \\
Total & & & \\
\hline
\end{tabular}

CHF, chronic heart failure; SAS, specific activity scale. Events (primary endpoints) in parentheses occurred after secondary endpoints in the same patient and were not included in the combined number.

experienced a primary event by the end of the study period.

\section{Safety Monitoring}

Sequential safety monitoring was carried out throughout the study by an independent Safety and Data Monitoring Committee, but no interim analysis of efficacy was conducted. Adverse events were classified using the WHOART dictionary and adverse events for which a causal relationship with drug treatment was not excluded were treated as adverse drug reactions.

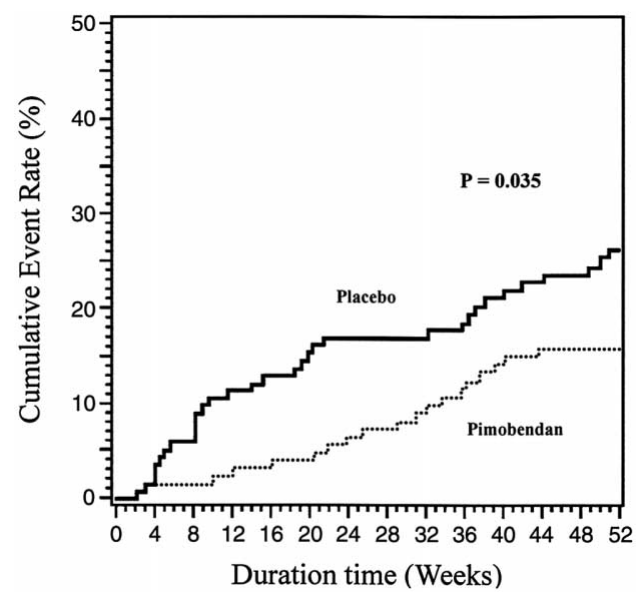

Fig 1. Kaplan-Meier estimations of cumulative rates of combined (primary + secondary endpoints) cardiac events in the pimobendan and placebo groups.

\section{Results}

\section{Study Population}

Between December 1995 and September 1998, 306 patients who gave written consent to participate were considered for enrollment (Table 1). Eight patients were found to be ineligible at the time of randomization and were excluded. Study medication was not initiated after randomization for miscellaneous reasons (Table 1) in 8 patients assigned to pimobendan, and in 11 assigned to placebo. Thus 279 patients were randomly assigned to

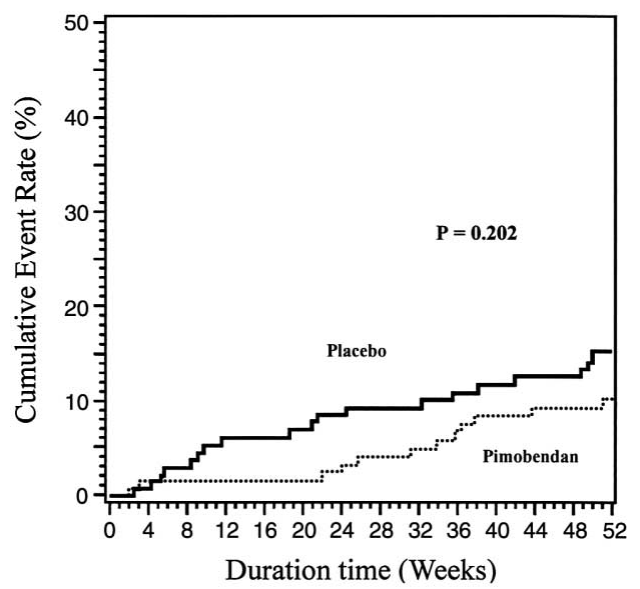

Fig 2. Kaplan-Meier estimations of cumulative rates of primary (primary endpoints) cardiac events in the pimobendan and placebo groups.

Table 4 Kaplan-Meier Analysis of the Cumulative Incidence Rates of Cardiac Events

\begin{tabular}{lccccc}
\hline \hline Analysis & No. of events & $\begin{array}{c}\text { Cumulative } \\
\text { incidence }\end{array}$ & $\begin{array}{c}\text { Estimated } \\
\text { HR }\end{array}$ & $95 \%$ CI & $\begin{array}{c}\text { p value of } \\
\text { log-rank test }\end{array}$ \\
\hline $\begin{array}{c}\text { Combined primary and } \\
\text { secondary endpoints }\end{array}$ & & & & & \\
$\quad \begin{array}{l}\text { Pimobendan }(n=138) \\
\text { Placebo }(n=138)\end{array}$ & 19 & $15.9 \%$ & 0.55 & $0.31-0.97$ & 0.035 \\
$\begin{array}{c}\text { Primary endpoints } \\
\text { Pimobendan }(n=138)\end{array}$ & 33 & $26.3 \%$ & & & \\
$\quad$ Placebo $(n=138)$ & 12 & $10.1 \%$ & 0.63 & $0.30-1.29$ & 0.202 \\
\hline
\end{tabular}

HR, hazard ratio; CI, confidence interval. 
treatment (139 to pimobendan and 140 to placebo). Three patients (1 with LVEF $>60 \%$, 1 with sinus arrest, and 1 with wide variations in the SAS scores during the pre-treatment period) were excluded from all analyses before unblinding of their treatment assignments. The baseline clinical characteristics of the 276 patients with full analysis data sets, evenly distributed between treatment with pimobendan and placebo, are summarized in Table 2 . Nearly $80 \%$ of patients (107 patients in the pimobendan group and 111 patients in the placebo group) were treated with $1.25 \mathrm{mg}$ twice daily of pimobendan or the equivalent dose of placebo throughout the entire period of study.

Study medication was discontinued because of adverse events in 18 patients from each group. Four adverse events in the pimobendan-treated group were unrelated to drug therapy and were noncardiovascular. Nine adverse events in the placebo-treated group were unrelated to drug therapy, and included 2 hospitalizations for acute myocardial infarction. In addition, 9 patients in the pimobendan-treated group and 7 in the placebo-treated group exited the study. The reasons for exiting the study that were not related to safety problems included withdrawal of informed consent or loss of follow up etc. Therefore, treatment was completed per protocol by 111 patients treated with pimobendan and 113 patients treated with placebo.

\section{Cardiac Events}

During the 52-week study period, one patient died suddenly in each treatment group, there were 12 hospitalizations for worsening heart failure in the pimobendan-treated group vs 19 in the placebo-treated group, and 26 secondary adverse cardiac events (secondary endpoints) occurred. The secondary adverse cardiac events were a decrease in SAS score and the addition or increase in doses of concomitant treatment in 8 pimobendan-treated vs 18 placebo-treated patients. Because 5 hospitalizations for worsening heart failure ( 1 in the pimobendan, 4 in the placebo group) occurred after the secondary adverse cardiac events (secondary endpoints) in the same patients, the primary analysis of combined primary and secondary endpoints included a total of 52 events: 19 in the pimobendan-treated group, and 33 in the placebo-treated group (Table 3 ).

The cumulative incidence rates of combined primary and secondary endpoints were $15.9 \%$ in the pimobendan-treated group and $26.3 \%$ in the placebo-treated group (Fig 1, Table 4), corresponding to an estimated $45 \%$ risk reduction (95\% CI of hazard ratio: $0.31-0.97$, logrank test: $\mathrm{p}=0.035$ ). The cumulative incidence rates of the primary endpoints were $10.1 \%$ and $15.3 \%$, respectively (Fig 2, Table 4), corresponding to an estimated hazard ratio of 0.63 without significant difference, but comparable to that of the combined primary and secondary endpoints.

\section{Changes in SAS}

Fig 3 and Table 5 show the time course of the SAS scores, expressed as LSMeans \pm SE, in each treatment group. There was no significant difference at baseline between the 2 groups. The analysis of covariance using the baseline values as covariates revealed a significant overall improvement in the pimobendan-treated group compared with the placebo-treated group $(\mathrm{p}=0.045)$ and this improvement was judged to be nearly uniform over the study period, because the interaction between the 2 groups and the time points was not significant $(\mathrm{p}=0.18)$. The difference in SAS scores between baseline and 52 weeks was significant in the pimobendan-treated group $(\mathrm{p}=0.024)$, consistent with a treatment-related increase in daily physical activities. In contrast, the difference in the placebo-treated group was not statistically significant $(\mathrm{p}=0.318)$.

\section{Changes in NYHA Functional Classification}

In the placebo-treated group, NYHA functional class improved in $20.9 \%$ of patients from the baseline, remained unchanged in $54.5 \%$ and was aggravated in $24.6 \%$, whereas in the pimobendan-treated group the NYHA improved in $34.6 \%$, remained unchanged in $54.1 \%$ and was aggravated in $11.3 \%$ of the patients. The difference between the 2 groups was statistically significant $(\mathrm{p}=0.0013)$.

\section{Changes in LVEF, ANP and CTR}

Table 6 summarizes the treatment-related changes in the indices of LVEF, ANP and CTR measured between baseline and the end of the study period. Mean LVEF at baseline and 52 weeks was $32.8 \pm 8.1 \%$ vs $38.7 \pm 13.0 \%$ in the pimobendan-treated group, and $32.7 \pm 8.5 \%$ vs $35.8 \pm 11.2 \%$ in the placebo-treated group. Analysis of covariance revealed that the increase in LVEF by 52 weeks was signif-

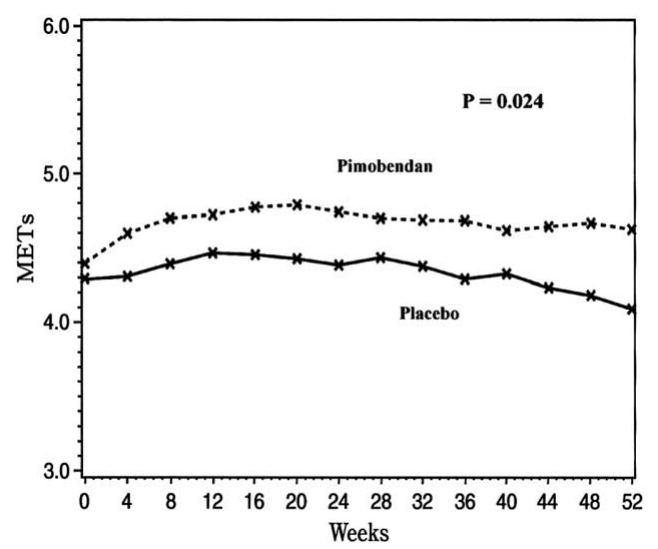

Fig 3. Time course of the Specific Activity Scale (SAS) scores expressed as LSMeans \pm SE in each treatment group.

Table 5 Time Trends of the Specific Activity Scale (SAS)

\begin{tabular}{lccc}
\hline \hline & $\begin{array}{c}\text { Pimobendan }(n=134) \\
\text { LSMean } \pm S E\end{array}$ & $\begin{array}{c}\text { Placebo }(n=135) \\
\text { LSMean } \pm S E\end{array}$ & $\begin{array}{c}\text { 95\% CI of } \\
\text { difference }\end{array}$ \\
\hline Baseline & $4.39 \pm 0.12$ & $4.30 \pm 0.12$ & $-0.23,0.43$ \\
4 weeks & $4.66 \pm 0.12$ & $4.36 \pm 0.12$ & $-0.04,0.64$ \\
24 weeks & $4.79 \pm 0.13$ & $4.43 \pm 0.15$ & $-0.05,0.75$ \\
52 weeks & $4.68 \pm 0.15^{*}$ & $4.14 \pm 0.17$ & $0.09,0.98$ \\
\hline
\end{tabular}

CI, confidence interval. ${ }^{*} p=0.024$ v baseline. $F$ test of analysis of covariance using baseline values as covariates: Drug $(F=4.04$, $d f=1, p=0.045)$, Week $(F=1.73, d f=12, p=0.054)$, Drug/Week $(F=1.35, d f=12, p=0.18)$. 
Table 6 Treatment-Related Changes in LVEF, ANP and CTR

\begin{tabular}{cccc}
\hline \hline & Pimobendan & Placebo & Test \\
\hline LVEF $(\%)$ & $(n=102)$ & $(n=110)$ & \\
Baseline & $32.8 \pm 8.1$ & $32.7 \pm 8.5$ & \\
52 weeks & $38.7 \pm 13.0$ & $35.8 \pm 11.2$ & \\
ANP $($ pg/ml $)$ & $(n=97)$ & $(n=91)$ & \\
Baseline & $47.1 \pm 2.7$ & $60.0 \pm 2.5$ & \\
52 weeks & $36.5 \pm 2.7$ & $(n=9.0$ & \\
CTR $(\%)$ & $(n=98)$ & $55.2 \pm 6.1$ & \\
Baseline & $54.7 \pm 6.2$ & $56.6 \pm 7.2$ & $p=0.002$ \\
52 weeks & $54.3 \pm 6.9$ & & \\
\hline
\end{tabular}

Analysis of covariance using baseline values as covariates. LVEF, left ventricular ejection fraction; ANP, serum atrionatriuretic peptide; CTR, cardiothoracic ratio. Values are mean $\pm S D$.

Table 7 Severe Adverse Events in Each Treatment Group During the Study Period

\begin{tabular}{lcc}
\hline \hline Event & Pimobendan $(n=138)$ & Placebo $(n=138)$ \\
\hline Musculo-skeletal system disorder & 2 & 0 \\
Nervous system disorder & $2(1)$ & 2 \\
Visual disorder & 0 & 1 \\
Psychiatric disorder & 0 & 1 \\
Gastrointestinal system disorder & 2 & $3(1)$ \\
Liver and biliary system disorder & 2 & 0 \\
Metabolic and nutritional disorder & 1 & $3(1)$ \\
Cardiovascular disorder, general & 0 & $1(1)$ \\
Myo-, endo-, pericardial or valvular disorder & $1(1)$ & 2 \\
Heart rate and rhythm disorder & $3(1)$ & $2(2)$ \\
Vascular (extracardiac) disorder & 1 & 1 \\
Respiratory system disorder & $4(1)$ & 6 \\
Red blood cell disorder & 1 & 0 \\
Urinary system disorder & 0 & 2 \\
Neoplasm & 1 & 1 \\
Resistance mechanism disorder & 2 & 0 \\
Whole body disorder & $16(5)$ & $24(2)$ \\
Total no. of severe adverse events & $38(9)$ & $49(7)$ \\
Total no. of patients with severe adverse events & $30(9)$ & $44(7)$ \\
\hline
\end{tabular}

Numbers in parentheses indicate severe adverse drug reactions.

icant in favor of the pimobendan-treated group ( $\mathrm{p}=0.044)$. Furthermore, serum ANP levels significantly decreased from $47.1 \pm 2.7$ to $36.5 \pm 2.7 \mathrm{pg} / \mathrm{ml}$ in the pimobendan-treated group, but increased from $54.0 \pm 2.5$ to $60.9 \pm 3.0 \mathrm{pg} / \mathrm{ml}$ in the placebo-treated group by 52 weeks ( $\mathrm{p}=0.0001$ ). Finally, CTR increased from $55.2 \pm 6.1 \%$ to $56.6 \pm 7.2 \%$ in the placebo-treated group, but remained unchanged in the pimobendan-treated group $(54.7 \pm 6.2 \%$ to $54.3 \pm 6.9 \%)$, the difference that was highly significant $(\mathrm{p}=0.002)$.

\section{Adverse Events}

Pimobendan was well tolerated. There were no significant differences between the pimobendan- and placebotreated groups with regard to blood pressure and heart rate during the entire study period. Adverse events were reported in 103 patients $(74.6 \%)$ in the pimobendan-treated group and 100 patients $(72.5 \%)$ in the placebo-treated group. Severe adverse events were observed in 30 patients $(21.7 \%)$ in the pimobendan-treated group and 44 patients (31.9\%) in the placebo-treated group (Table 7). Severe adverse drug reactions were reported in 9 patients $(6.5 \%)$ in the pimobendan-treated group and in 7 patients $(5.1 \%)$ in the placebotreated group. Pimobendan treatment was not associated with an increased incidence of arrhythmias.

\section{Discussion}

Against recent pessimism expressed with respect to the long-term safety and efficacy of existing cardiotonic drugs, ${ }^{24,25}$ the present study found that long-term treatment with pimobendan, an inotropic agent, reduced the incidence of adverse cardiac events, including worsening of heart failure and a decrease in functional capacity, without a significant effect on mortality in patients with NYHA functional classes IIm and III CHF.

CHF is treated on the basis of its severity, cause and pathology in individual patients with priority given to the prevention of mortality and the improvement in the quality of life (QOL). That is, in patients with mild CHF, the primary objective is prevention of mortality and a decrease in incidence of clinical interventions such as hospitalization and the addition or increased dosage of therapeutic drugs. On the other hand, in patients with moderate to severe CHF who develop symptoms affecting their physical activities and eventually affecting their social life, the primary objective of treatment is not only prevention of mortality and a decrease in incidence of the clinical interventions, but also improvement in the level (threshold) of physical activity causing the symptoms and improvement of QOL. In the present trial, in order to assess the effect of long-term administration of pimobendan on the mortality 
and morbidity of patients with CHF, cardiac events such as heart failure death, sudden death and hospitalization because of worsening heart failure were defined as the primary endpoints, and a decrease in physical activity, the addition or dosage increase of concomitant drugs because of worsening heart failure and non-cardiovascular deaths were secondary endpoints. The primary analysis was carried out with regard to cardiac events combining primary and secondary endpoints, and the results showed that the cumulative incidence of combined adverse cardiac events was $45 \%$ lower in the pimobendan group than in the placebo group $(\mathrm{p}=0.035)$, suggesting that pimobendan has a longterm beneficial effect in the treatment of CHF.

In a study of 52 ambulatory patients in NYHA functional class III-IV heart failure, adding 5 or $10 \mathrm{mg} /$ day of pimobendan to a conventional drug regimen for 4 weeks was associated with a significant increase in maximal exercise duration and peak oxygen uptake compared with placebo! ${ }^{11}$ Furthermore, in a multicenter randomized trial of pimobendan, $2.5,5.0$ or $10 \mathrm{mg} /$ day vs placebo for 12 weeks, including nearly 200 patients with moderate heart failure, active therapy significantly increased exercise capacity and QOL, and was associated with fewer hospitalizations for heart failure than placebo $!^{2}$ It is noteworthy that the effects of pimobendan did not follow a simple dose-response relationship, as maximum efficacy was associated with the $5 \mathrm{mg} /$ day dose, and a lesser efficacy was observed with the $10 \mathrm{mg} /$ day dose.

Long-term therapy was evaluated in the Pimobendan in Congestive Heart Failure (PICO) trial, which randomly assigned 317 outpatients with NYHA functional class II-III CHF to receive placebo vs pimobendan 2.5 or $5 \mathrm{mg} /$ day for 6 months $!^{15}$ Though pimobendan increased exercise duration significantly compared with placebo, no significant effects were observed on peak oxygen consumption or QOL. There were 11 deaths among the 108 placebo-treated patients (10.2\%) and 36 among the 209 pimobendantreated patients (17.2\%). In contrast, in a smaller, 6-month, double-blind randomized study of patients with symptomatic heart failure, 5 of 11 patients who received placebo were withdrawn because of worsening heart failure, compared with none of the patients treated with pimobendan ${ }^{16}$ In addition, pimobendan significantly improved physical activity, manifesting as a significant increase in mean SAS score at the end of therapy, whereas in the placebo-treated group, the mean SAS score remained unchanged throughout the study period.

In the present study, one patient treated with pimobendan died. The present study had a smaller proportion of patients with severe CHF than in the PICO trial, as indicated by a higher mean LVEF of $33 \%$ vs $26-28 \%$ in PICO. Also, more patients $(80 \%)$ were treated with a lower dose of pimobendan as compared with the PICO trial.

The most direct evaluation of heart failure consists of inquiring about symptoms at rest and during exertion. Because the symptoms are usually accentuated during exertion, it has been suggested that the functional status of patients with CHF could be reliably indicated by exercise capacity.6-28 However, daily activities do not demand a maximal energy expenditure. Several clinical trials of CHF have included the 'Living With Heart Failure' questionnaire as a measure of QOL ${ }^{29,30}$ Although changes in exercise capacity and in physical activity assessed from the overall questionnaire score have been shown to correlate weakly, though significantly, discrepancies between these
2 parameters have been regularly noted, illustrating the distinction between objective measures and subjective assessment of disability!2 SAS, the clinical scale used here, has been shown to predict exercise capacity more reliably, with a correlation coefficient between SAS and peak oxygen consumption of $0.78(\mathrm{p}<0.001)$ measured in 51 patients. ${ }^{21}$ This reproducible score was associated with a mean difference of $0.4 \pm 0.5$ Mets in inter-observer variability, prompting us to consider changes in functional capacity $\geq 1$ Mets as reliable and clinically relevant.

The primary objective of the present clinical trial was to evaluate the effect of long-term administration of pimobendan on the prognosis of heart failure. Taking the therapeutic purpose for heart failure into consideration, it is also necessary to examine improvements in symptoms or function in the areas of QOL, cardiac function etc, in addition to the evaluation of events corresponding to aggravation of prognosis. In view of this, SAS, NYHA functional classification, LVEF, ANP and CTR were analyzed as the secondary variables. Treatment with pimobendan was associated with improvement in physical activity, suggested by an increase in SAS score and improvement of NYHA functional classification. The analysis of LVEF, ANP and CTR also showed a treatment-related improvement in each variable.

Much attention has been focused on a possible direct toxic effect of pimobendan on myocytes, exacerbating arrhythmias, enhancing neurohormonal activity, and increasing the mortality of patients with CHF. However, a beneficial effect of pimobendan has been found in several experimental studies.-7,31,32 In the skinned myocardial fiber, calcium sensitizers shifted the $\mathrm{Ca}^{2+}$-force curve to the left, increasing the degree of contractile force generated at a given $\mathrm{Ca}^{2+}$ concentration; 4,5,7,31 however, $\mathrm{Ca}^{2+}$ sensitizers may adversely inhibit cardiac relaxation by the slow detachment of $\mathrm{Ca}^{2+}$ from troponin $\mathrm{C}$, with elevated myocardial tension during diastole?3,34 Pimobendan offsets this impairment of diastolic relaxation by its low-level inhibitory effect of phosphodiesterase $3^{35}$ When initial heat liberated from guinea pig papillary muscles and the integral stresstime were measured simultaneously using myothermal equipment, both were substantially increased by pimobendan, whereas the slope of the function relating to initial heat and the developed integral tension-time remained unchanged6 In patients with idiopathic dilated cardiomyopathy and moderate CHF, the systemic hemodynamic actions induced by pimobendan were associated with advantageous effects on myocardial oxygen consumption ${ }^{36}$ Therefore, the increase in myocardial oxygen force by pimobendan is accomplished in a more economical way, making this agent better suited for long-term treatment of heart failure.

There is growing evidence that immunologic responses mediated by certain cytokines, including tumor necrosis factor $\alpha$, interleukin- $\mathbb{\beta}$, interleukin- 6 etc, may play an important pathogenic role in the development of heart failure ${ }^{37-41}$ Several clinical studies have demonstrated that patients with CHF express excessive levels of those cytokines in plasma, ${ }^{42-45}$ and on the basis of those observations, great interest has been generated in new therapies to modulate those cytokines. ${ }^{46}$ Pimobendan inhibits the production of tumor necrosis factora in human peripheral mononuclear cells, ${ }^{47}$ and of $\mathrm{NO}$ in cultured macrophages in vitro 48 More recently, it was reported that myocardial protein levels of tumor necrosis factor $\alpha$, interleukin- $\beta$, and interleukin- 6 were substantially reduced by pimoben- 
dan, together with a significant reduction in intracardiac NO production and inducible nitric oxide synthase (iNOS) gene expression. 49 Although the mechanism by which pimobendan inhibits the production of proinflammatory cytokines and iNOS gene expression has not been elucidated, it has recently been reported that pimobendan inhibits the activation of transcription factor nuclear factorK B 50 These data suggest that the therapeutic effects of pimobendan observed in the present study may be attributable, in part, to its immunomodulating or anticytokine properties.

In conclusion, the present study demonstrated that longterm concurrent treatment with a low dose of pimobendan ( $1.25 \mathrm{mg}$ twice daily) in patients with moderate CHF is well tolerated, reduces morbidity, and improves physical activity without a significant increase in adverse effects. However, it does not influence the risk of mortality.

\section{Acknowledgments}

The investigators would like to thank the patients who participated in this study. This study was supported by a grant from Nippon Boehringer Ingelheim, Japan.

\section{References}

1. Packer M. The development of positive inotropic agents for chronic heart failure: How have we gone astray? J Am Coll Cardiol 1993; 22(4 Suppl A): 119A-126A.

2. Ho KKL, Pinsky JL, Kannel WB, Levy D. The epidemiology of heart failure: The Framingham Study. J Am Coll Cardiol 1993; 22(4 Suppl A): 6A-13A.

3. Sasayama S. What do the newer inotropic drugs have to offer? Cardiovasc Drugs Ther 1992; 6: 15-18.

4. Fujino K, Sperelakis N, Solaro RJ. Sensitization of dog and guinea pig heart myofilaments to $\mathrm{Ca}^{2+}$ activation and the inotropic effect of pimobendan: Comparison with milrinone. Circ Res 1988; 63: $911-$ 922.

5. van Meel JCA, Entzeroth M, Redemann N, Haigh RM. Effects of pimobendan and its metabolite on myofibrillar calcium responsiveness and ATPase activity in the presence of inorganic phosphate. Arzneim-Forsch/Drug Res 1995; 45: 136-141.

6. Holubarsch C. New inotropic concepts: Rationale for and differences between calcium sensitizers and phosphodiesterase inhibitors. Cardiology 1997; 88(Suppl2): 12-20.

7. Fraker LD, Van Eyk J, Solaro RJ. Reversal of phosphate induced decreases in force by the benzimidazole pyridazinone, UD-CG212 CL, in myofilaments from human ventricle. Mol Cell Biochem 1997; 176: $83-88$.

8. Hagemeijer F, Brand HJ, Roth W. Cardiovascular effects and plasma level profile of pimobendan (UD-CG $115 \mathrm{BS}$ ) and its metabolite UDCG 212 in patients with congestive heart failure after single and repeated oral dosing. J Cardiovasc Pharmacol 1989; 14: 302-310.

9. Walter M, Liebens I, Goethals H, Renard M, Dresse A, Bernard R. Pimobendane (UD-CG 115 BS) in the treatment of severe congestive heart failure: An acute haemodynamic cross-over and double-blind study with two different doses. Br J Clin Pharmacol 1988; 25: $323-$ 329.

10. Renard M, Walter M, Liebens I, Dresse A, Bernard R. Pimobendane (UD-CG 115 BS) in chronic congestive heart failure: Short-term and one-month effects of a new inotropic vasodilating agent. Chest 1988; 93: $1159-1164$

11. Katz SD, Kubo SH, Jessup M, Brozena S, Troha JM, Wahl J, et al. A multicenter, randomized, double-blind, placebo-controlled trial of pimobendan, a new cardiotonic and vasodilator agent, in patients with severe congestive heart failure. Am Heart J 1992; 123: 95-103.

12. Kubo SH, Gollub S, Bourge R, Rahko P, Cobb F, Jessup M, et al for the Pimobendan Multicenter Reseach Group. Beneficial effects of pimobendan on exercise tolerance and quality of life in patients with heart failure: Results of a multicenter trial. Circulation 1992; 85: 942-949.

13. Remme WJ, Krayenbuerhl HP, Baumann G, Frick MH, Haehl M, Nehmiz G, et al for the Pimobendan-Enalapril Study Group. Longterm efficacy and safety of pimobendan in moderate heart failure: A double-blind parallel 6-month comparison with enalapril. Eur Heart J 1994; 15: $947-956$.
14. Kato K. Clinical efficacy and safety of pimobendan in treatment of heart failure: Experience in Japan. Cardiology 1997; 88(Suppl 2): 28 36.

15. Lubsen J, Just H, Hjalmarsson AC, La Framboise D, Remme WJ, Heinrich-Nols J, et al for the Pimobendan in Congestive Heart Failure (PICO) investigators. Effect of pimobendan on exercise capacity in patients with heart failure: Main results from the Pimobendan in Congestive Heart Failure (PICO) trial. Heart 1996; 76: 223-231.

16. Sasayama S, Asanoi H, Kihara Y, Yokawa S, Terada Y, Yoshida S, et al. Clinical effects of long-term administration of pimobendan in patients with moderate congestive heart failure. Heart Vessels 1994; 9: $113-120$.

17. Tsuji T, Masuda H, Imagawa K, Haraikawa M, Shibata K, Kono M, et al. Stability of human atrial natriuretic peptide in blood samples. Clin Chim Acta 1994; 225: 171 - 177.

18. Folland ED, Parisi AF, Moynihan PF, Jones DR, Feldman CL, Two DE. Assessment of left ventricular ejection and volumes by real-time, two-dimensional echocardiography: A comparison of cineangiographic and radionuclide techniques. Circulation 1979; 60: 760-766.

19. Kronik G, Slany J, Mosslacher H. Comparative value of eight Mmode echocardiographic formulas for determining left ventricular stroke volume: A correlative study with thermodilution and left ventricular single-plane cineangiography. Circulation 1979; 60: 13081316.

20. Nosir YFM, Fioretti PM, Vletter WB, Boersma E, Salustri A, Tjoa Postma J, et al. Accurate measurment of left ventricular ejection fraction by three-dimensional echocardiography. A comparison with radionuclide angiography. Circulation 1996; 94: 460-466.

21. Sasayama S, Asanoi H, Ishizaka S, Miyagi K. Evaluation of functional capacity of patients with congestive heart failure. In: Yasuda $\mathrm{H}$, Kawaguchi $\mathrm{H}$, editors. New aspects in the treatment of failing heart. Tokyo: Springer-Verlag; 1992: 113-117.

22. Feldman AM, Bristow MR, Parmley WW, Carson PE, Pepine CJ, Gilbert EM, et al for the Vesnarinone Study Group. Effects of vesnarinone on morbidity and mortality in patients with heart failure. $N \mathrm{Engl}$ J Med 1993; 329: 149-155.

23. Freedman LS. Tables of the number of patients required in clinical trials using the logrank test. Stat Med 1982; 1: 121-129.

24. Packer M, Carver JR, Rodeheffer RJ, Ivanhoe RJ, Dibianco R, Zeldis $\mathrm{SM}$, et al for the PROMISE Study Research Group. Effect of oral milrinone on mortality in severe chronic heart failure. $N$ Engl $\mathrm{J} \mathrm{Med}$ 1991; 325: $1468-1475$.

25. Cohn JN, Goldstein SO, Greenberg BH, Lorell BH, Bourge RC, Jaski $\mathrm{BE}$, et al for the Vesnarinone Trial Investigators. A dose-dependent increase in mortality with vesnarinone among patients with severe heart failure. N Engl J Med 1998; 339: 1810-1816.

26. Kim S, Yamabe H, Yokoyama M. Hemodynamic characteristic during treadmill and bicycle exercise in chronic heart failure: Mechanism for different responses of peak oxygen uptake. Jpn Circ J 1999; 63: $965-970$.

27. Koike A, Koyama Y, Itoh H, Adachi H, Marumo F, Hiroe M. Prognostic significance of cardiopulmonary exercise testing for 10-year survival in patients with mild to moderate heart failure. Jpn Circ J 2000; 64: 915-920.

28. Tanehata M, Adachi H, Oshima S, Taniguchi K, Itoh H, Hasegawa A, et al. The time from anaerobic threshold (AT) to respiratory compensation point reflects the rate of aerobic and anaerobic metabolism after the AT in chronic heart failure patients. Jpn Circ J 1999; 63: $274-277$.

29. Gorkin L, Norvell NK, Rosen RC, Charles E, Shumaker SA, McIntyre $\mathrm{KM}$, et al. Assessment of quality of life as observed from the baseline data of the studies of left ventricular dysfunction (SOLVD) trial quality-of-life substudy. Am J Cardiol 1993; 71: 1069-1073.

30. Rector TS, Tschumperlin LK, Kubo SH, Bank AJ, Francis GS, McDonald KM, et al. Use of the Living With Heart Failure questionnaire to ascertain patients' perspectives on improvement in quality of life versus risk of drug-induced death. J Card Fail 1995; 1: 201-206.

31. Rueregg JC, Morano I. Calcium-sensitivity modulation of cardiac myofibrillar proteins. J Cardiovasc Pharmacol 1989; 14(Suppl III): S20-S23.

32. Goto Y, Hata K. Mechanoenergetic effect of pimobendan in failing dog hearts. Heart Vessels 1997; (Suppl 12): 103-105.

33. Senzaki H, Isoda T, Paolocci N, Ekelund U, Hare JM, Kass DA. Improved mechanoenergetics and cardiac rest and reserve function of in vivo failing heart by calcium sensitizer EMD-57033. Circulation 2000; 101: 1040-1048.

34. Nielsen-Kudsk JE, Aldershvile J. Will calcium sensitizers play a role in the treatment of heart failure? J Cardiovasc Pharmacol 1995; 26(Suppl 1): S77-S84

35. Remme WJ. Inodilator therapy for heart failure. Early, late, or not at 
all? Circulation 1993; 87(SupplIV): IV97-IV107.

36. Hasenfuss G, Holubarsch C, Heiss HW, Just H. Influence of UDCG115 on hemodynamics and myocardial energetics in patients with idiopathic dilated cardiomyopathy. Am Heart J 1989; 118: 512 - 519 .

37. Gulick T, Chung MK, Pieper SJ, Lange LG, Schreiner GF. Interleukin 1 and tumor necrosis factor inhibit cardiac myocyte $\beta$-adrenergic responsiveness. Proc Natl Acad Sci USA 1989; 86: 6753-6757.

38. Oyama J, Shimokawa H, Momii H, Cheng X, Fukuyama N, Arai Y, et al. Role of nitric oxide and peroxynitrite in the cytokine-induced sustained myocardial dysfunction in dogs in vivo. J Clin Invest 1998; 101: $2207-2214$

39. Finkel MS, Oddis CV, Jacob TD, Watkins SC, Hattler BG, Simmons RL. Negative inotropic effects of cytokines on the heart mediated by nitric oxide. Science 1992; 257: 387-389.

40. Yokoyama T, Vaca L, Rossen RD, Durante W, Hazarika P, Mann DL. Cellular basis for the negative inotropic effects of tumor necrosis factora in the adult mammalian heart. J Clin Invest 1993; 92: $2303-2312$.

41. Oral H, Dorn GW 2nd, Mann DL. Sphingosine mediates the immediate negative inotropic effects of tumor necrosis factora in the adult mammalian cardiac myocyte. J Biol Chem 1997; 272: 4836-4842.

42. Levine B, Kalman J, Mayer L, Fillit HM, Packer M. Elevated circulating levels of tumor necrosis factor in severe chronic heart failure. N Engl J Med 1990; 323: 236-241.

43. Matsumori A, Yamada T, Suzuki H, Matoba Y, Sasayama S. Increased circulating cytokines in patients with myocarditis and cardiomyopathy. Br Heart J 1994; 72: 561-566.

44. Kubota T, McNamara DM, Wang JJ, Trost M, McTiernan CF, Mann DL, et al for the VEST investigators for TNF genotype analysis. Effects of tumor necrosis factor gene polymorphisms on patients with congestive heart failure. Circulation 1998; 97: 2499-2501.

45. MacGowan GA, Mann DL, Kormos RL, Feldman AM, Murali S. Circulating interleukin-6 in severe heart failure. Am J Cardiol 1997; 79: $1128-1131$.

46. Sasayama S, Matsumori A, Kihara Y. New insights into the pathophysiological role for cytokines in heart failure. Cardiovasc Res 1999; 42: 557-564.

47. Matsumori A, Okada I, Shioi T, Furukawa Y, Nakamura T, Ono K, et al. Inotropic agents differentially inhibit the induction of nitric oxide synthase by endotoxin in cultured macrophages. Life Sci 1996; 59: PL121-PL125.

48. Matsumori A, Ono K, Sato Y, Shioi T, Nose Y, Sasayama S. Differential modulation of cytokine production by drugs: Implications for therapy in heart failure. J Mol Cell Cardiol 1996; 28: 2491-2499.

49. Iwasaki A, Matsumori A, Yamada T, Shioi T, Wang W, Ono K, et al. Pimobendan inhibits the production of proinflammatory cytokines and gene expression of inducible nitric oxide synthase in a murine model of viral myocarditis. J Am Coll Cardiol 1999; 33: 1400-1407.

50. Matsumori A, Nunokawa Y, Sasayama S. Pimobendan inhibits the activation of transcription factor NFK B: A mechanism which explains its inhibition of cytokine production and inducible nitric oxide synthase. Life Sci 2000; 67: 2513-2519.

\section{Appendix}

Institutions and Investigators Participating in EPOCH

Executive Committee: K. Kato (chairman), M. Iizuka, Y. Yazaki, S. Sasayama Study Coordinator: M. Nakashima (Hamamatsu Medical College)

Study Statistician: Y. Ohashi (University of Tokyo)

Steering Committee: K. Kato (chairman)

(1) Study Events Subcommittee: S. Sasayama (chairman), T. Izumi, M. Hori, M. Matsuzaki, H. Asanoi

(2) Study Protocol Subcommittee: M. Iizuka (chairman), K. Taniguchi, T. Serizawa (Saitama Medical School), T. Katagiri, H. Ito, H. Hayashi

(3) Recruitment Subcommittee: Y. Yazaki (chairman), A. Kitabatake, K. Shirato (Tohoku University), A. Takeshita

Safety \& Data Monitoring Committee: S. Kimata (chairman: Tokyo Employee's Pension Hospital), M. Nakashima, Y. Ohashi

Publishing Committee: S. Sasayama (chairman), M. Matsuzaki, Y.Ohashi

Participating Institutions and Investigators: Hokkaido University: A. Kitabatake, T. Koya; Sapporo City General Hospital: N. Kato, N. Matsuo; Sapporo Kosei General Hospital: K. Kanda, H. Okada; NTT Sapporo Hospital: K. Tomita; Hakodate Central General Hospital: T. Sugawara; Date Red Cross Hospital: S. Takechi; Nikko Memorial Hospital: T. Shogase; Rabour Welfare Corporation Kushiro Rosai Hospital: H. Sato, T. Murasaki;
Wakkanai City Hospital: Y.Yamada; Iwate Medical University: K. Hiramori, I. Segawa; Tohoku Rosai Hospital: T. Nunokawa; Tohoku Welfare Pension Hospital: K. Nita, S. Sugawara; Sendai City Hospital: H. Odakura; Ishinomaki Red Cross Hospital: H. Sukegawa, N. Nozaki, J. Nitobe; Miyagi Prefectural Semine Hospital: H.Takeda; Yamagata University: H. Tomoike, S. Yamaguchi; Yamagata Prefectural Central Hospital: T. Araki, T. Goto; Yamagata Prefectural Nihonkai Hospital: M. Oguma, K. Honma, M. Matsui; Dokkyo University: M. Iizuka, H. Maezawa; Jichi Medical School: K. Shimada, U.Ikeda; Gunma Prefectural Cardiovascular Center: K. Taniguchi, S. Oshima, H. Adachi, H. Hoshizaki, T. Toyama; Cardiovascular Institute: K. Kato, H. Ito, M. Kato; University Of Tokyo: Y. Yazaki (at present, International Medical Center of Japan), M. Omata, S. Momomura, S. Sugiura, A. Aoyagi, I. Yokoyama; Showa University: T. Katagiri, E. Geshi, M. Nagayama; International Medical Center Of Japan: N. Akatsuka, O. Okazaki, K. Izumo; Keio University: S. Ogawa, H. Mitamura, T. Yoshikawa; Jikei University (Aoto Hospital): S. Mochizuki, M. Ishiki; Tokyo Metropolitan Hiroo General Hospital: T. Motomiya, O. Yanase; Tokyo Metropolitan Geriatric Hospital: S. Ueda; Tokyo Women's Medical University: H. Kasanuki, M. Kawana; Yokohama Municipal Citizen's Hospital: T.Takahashi, K. Negishi, H. Shiraki; Yokohama City University: H. Ochiai; Yokohama City University Urafune Hospital: K. Kimura, T.Endo; Saiseikai Yokohamashi Nambu Hospital: Y.Yoshii, R. Sawada; Yokohama City Kowan Hospital: N. Miyazaki, A. Iwata; Kanto Rosai Hospital; T. Hasegawa, M. Hayashi; Yokosuka Kyosai Hospital: M. Korenaga, K. Aonuma; Kitasato University: T. Izumi, S. Kurokawa, M. Shimizu, T. Sasaoka; Showa University Fujigaoka Hospital: Y. Takeyama, T. Tsutsumi, M. Kondo; Niigata University: Y. Aizawa, M. Kodama, Y. Okura, S. Fujita; Kido Hospital; T. Tsuda; Tsubame Rosai Hospital: K. Watanabe; Saiseikai Niigata Daini Hospital: T.Funazaki, Y.Tamura, M. Tamura; Niigata Rosai Hospital: K. Kodera; Niigata Prefectural Central Hospital: S. Takano, M. Suzuki; Hokushin General Hospital: T. Takamoto; Toyama Medical And Pharmaceutical University: H. Inoue, H. Asanoi, T. Nozawa; Toyama Prefectural Central Hospital: T. Ishikawa, K. Iuchi; Koseiren Takaoka Hospital: H. Okuwa, K. Aoki; Kanazawa University: K. Kobayashi, S.Takata, A. Shimakura; Kanazawa Medical University: N. Takegoshi, S. Matsui, T. Asaji; Public Ushitsu Hospital; S. Hiromasa; Kanazawa Municipal Hospital: N. Sugimoto, M. Hirono; Public Central Hospital Of Matto Ishikawa: K. Kubota, H. Oda; Fukui Medical University: T.Ueda, J.Lee, H. Shimizu; Shizuoka General Hospital: M. Shirotani, K. Sakata, R. Nawada, K. Obayashi; Shizuoka City Hospital: A. Takizawa, T. Onodera; Tokai Central Hospital: S. Ogawa; Nagoya University: H. Hayashi (at present, Tsushima City Hospital), M. Hirai; Japanese Red Cross Nagoya First Hospital: M. Ono, Y. Hanaki, H. Kamiya; Japanese Red Cross Nagoya Second Hospital: H. Hirayama; Nagoya Ekisaikai Hospital: Y.Tanahashi, M. Okada; Daido Hospital: A. Sato; Shiga University Of Medical Science: M. Kinoshita, T. Tsutamoto; Shiga Medical Center For Adults: H. Uehata; Kyoto University: S. Sasayama, A. Matsumori; Takeda Hospital: S. Tamaki; Takeda General Hospital: T. Hashimoto; Mitsubishi Kyoto Hospital; A. Yoshida, Y. Kurosawa, S. Miki; Osaka University: M. Hori; Osaka Medical Center For Cancer And Cardiovascular Diseases: N. Awata, H. Tateyama; Osaka Rosai Hospital: J.Tanouchi, S. Hoshida, K. Iwai, T. Ito; National Cardiovascular Center: K. Miyatake, M. Yamagishi; Osaka Medical College: K. Kawamura, T. Hayashi; Kinki University: R. Katori, K. Ishikawa, M. Miyataka, S. Nakai, Y. Okabayashi; National Kinki-Chuo Hospital: H. Harada; Osaka Prefectural General Hospital; N.Hoki, T. Yamada; Osaka National Hospital: T.Hayashi, M. Asao; Kansai Electric Power Company Incorporated Hospital: A. Sakai, K. Ishii; Kobe National Hospital: T. Okada, M. Shimizu; Kobe University: M. Yokoyama, M.Takeuchi, H. Takaoka; Kobe City General Hospital: S. Morioka; Hyogo College Of Medicine: T. Iwasaki, T. Kondo, S. Nakao, S. Kobayashi, H. Masutani; Hyogo Prefectural Amagasaki Hospital: Y.Takatsu, Y.Sato; Himeji National Hospital: E. Matsuyama; Cardiovascular Institute Sakakibara Hospital: T. Kita, H. Nanba; Hiroshima City Hospital: H. Sato, Y. Shimatani; Hiroshima Red Cross Hospital \& Atomic Bomb Survivors Hospital: S. Kaseda, T. Yoshida, Y. Higuchi, S. Kinugawa; Yamaguchi University: M. Matsuzaki, T. Miura; Ehime Rosai Hospital: S. Ichiyama, S. Kobayashi; Ehime Prefectural Central Hospital: Y. Kazatani, H.Tatuno, H. Fukuda; Ehime Prefectural Mimamiuwa Hospital: K. Watanabe; National Sanatorium Ehime Hospital: M. Sekiya; Kochi Medical School: Y.Doi, H. Seo; Kyushu University: A. Takeshita, Y. Harasawa, Y. Ohara; Kitakyushu Municipal Medical Center: Y.Urabe, S. Suzuki, Y.Fukumoto; Fukuoka Red Cross Hospital: T. Inou, M. Tanaka; Kurume University Medical Center: Y.Koga; Nagasaki University: K. Yano, K. Baba, G. Toda; Kumamoto Chuo Hospital: K. Iwanaga, T. Saito, S. Oshima, S. Yamashita; Saiseikai Kumamoto Hospital: Ta. Honda, To.Honda 